\title{
NOTAS SOBRE O PLÁGIO E A CONTRAFAÇÃO
}

NOTES ON PLAGIARISM AND COUNTERFEITING

\section{LEONARDO ESTEVAM DE ASSIS ZANINI ${ }^{1}$}

ISSUE DOI: $10.21207 / 1983.4225 .460$

\section{RESUMO}

O presente artigo analisa, inicialmente, a ligação entre a personalidade do autor e sua obra, particularmente no que concerne ao direito de paternidade. A partir daí, procura deixar evidente a distinção entre o plágio e a contrafação, institutos que são muitas vezes confundidos pela doutrina e pelos tribunais, não obstante sua grande importância em nossa sociedade, em especial em razão do advento de novas tecnologias.

\footnotetext{
${ }^{1}$ Pós-doutorado em Direito Civil pelo Max-Planck-Institut für ausländisches und internationales Privatrecht (Alemanha). Pós-doutorado em Direito Penal pelo Max-PlanckInstitut für ausländisches und internationales Strafrecht (Alemanha). Doutor em Direito Civil pela USP (2013), com estágio de doutorado na Albert-Ludwigs-Universität Freiburg (Alemanha). Mestre em Direito Civil pela PUC-SP (2010). Bacharel em Direito pela USP (2000). Juiz Federal. Professor Universitário. Pesquisador do Núcleo de Pesquisa em Direito da Universidade de Araraquara (UNIARA). Pesquisador do grupo Novos Direitos $\mathrm{CNPq} / \mathrm{UFSCar}$. Autor de livros e artigos publicados nas áreas de Direito Civil, Direitos Intelectuais, Direito do Consumidor e Direito Ambiental. Foi bolsista da Max-PlanckGesellschaft e da CAPES. Foi Delegado de Polícia Federal (2002-2005). Foi Procurador do Banco Central do Brasil (2002). Foi Defensor Público Federal (2002). Foi Diretor da Associação dos Juízes Federais de São Paulo e Mato Grosso do Sul (2006-2011). Foi Diretor Acadêmico da Escola de Formação e Aperfeiçoamento de Servidores da Justiça Federal em São Paulo (2012-2014).
} 
Palavras-chave: Direito de Autor. Direitos intelectuais. Direitos da personalidade. Direito moral de autor. Direito ao reconhecimento da autoria. Plágio. Contrafação.

\section{ABSTRACT}

This article examines the connection between the author's personality and his work, particularly regarding to the right of paternity. From there, it seeks to clear the distinction between plagiarism and counterfeiting, institutes that are often confused by the doctrine and courts, despite its great importance in our society, especially due to the advent of new technologies.

Keywords: Copyright. Intellectual rights. Rights of personality. Moral rights of the author. Right of paternity. Plagiarism. Counterfeiting.

\section{INTRODUÇÃO}

O criador de uma obra normalmente quer ser reconhecido como seu autor, uma vez que a assinatura de um trabalho pode influir positivamente na forma como é visto pela sociedade. Assim, é certo que a boa fama, eventualmente adquirida pelo autor, está diretamente ligada à qualidade da manifestação de sua personalidade inserta na própria obra.

De fato, a assinatura de um trabalho é uma forma de se fazer conhecido em seu tempo. Também permite a imortalização da personalidade, que se torna presente também na posteridade, dado que o autor continua vivo em sua obra ${ }^{2}$.

Com efeito, mesmo antes do surgimento da legislação protetiva do autor, a ligação da obra ao nome já tinha a função de garantir ao criador uma forma de defesa contra usurpadores, que encontravam maiores dificuldades para lesar o autor de uma obra assinada. Assim procedeu, por

2 SCHACK, Haimo. Urheber- und Urhebervertragsrecht. 5. ed. Tübingen: Mohr Siebeck, 2010, p. 184. 
exemplo, Michelângelo, que em 1501, ao completar sua obra Pietá, prontamente assinou seu nome ${ }^{3}$.

Nessa linha, na medida em que a proteção do autor foi evoluindo, percebeu-se que o reconhecimento da autoria consistia no ponto mais fundamental e menos contestado dessa tutela, visto que diretamente ligado ao direito geral da personalidade ${ }^{4}$.

Trata-se, então, no quadro dos direitos da personalidade do autor, do tema central da proteção dos interesses pessoais e espirituais do criador". E tanto é assim que, conforme ensina Chinellato, "não se encontrou nenhuma legislação que não o reconheça, pois é considerado um dos primeiros e mais importantes direitos morais do autor" ${ }_{-}^{6}$. Por isso, a compreensão do direito ao reconhecimento da autoria, como veremos, é pressuposto imprescindível para o estudo do plágio e da contrafação, figuras que constituem violação da lei autoral ${ }^{8}$.

\section{O DIREITO AO RECONHECIMENTO DA AUTORIA}

O direito ao reconhecimento da autoria protege a vinculação personalística existente entre o autor e sua obra ${ }^{9}$. Encontra previsão ex-

3 SCHACK, Haimo. Urheber- und Urhebervertragsrecht. 5. ed. Tübingen: Mohr Siebeck, 2010, p. 184.

${ }^{4}$ STROWEL, Alain. Droit d'auteur et copyright: divergences et convergences. Paris: LGDJ, 1993, p. 496.

${ }^{5}$ DIETZ, Adolf; PEUKERT, Alexander. Vor $\S \S 12$ ff., $\S ~ 12-14,42$. In: SCHRICKER, Gerhard; LOEWENHEIM, Ulrich (Hrsg.). Urheberrecht: Kommentar. 4. ed. München: C. H. Beck, 2010, p. 871.

${ }^{6}$ CHINELLATO, Silmara Juny de Abreu. Direito de autor e direitos da personalidade: reflexões à luz do Código Civil. Tese para Concurso de Professor Titular de Direito Civil da Faculdade de Direito da Universidade de São Paulo. São Paulo: Universidade de São Paulo, 2008. p. 166.

${ }^{7}$ No que diz respeito aos países que adotam o sistema do copyright, é certo que a legislação normalmente não contém normas gerais sobre o reconhecimento da paternidade. No entanto, mesmo nesses ordenamentos avessos aos direitos da personalidade do autor, há disposições que permitem inferir a existência do direito ao reconhecimento da autoria, como é o caso da obrigação de indicar a fonte (LIPSZYC, Delia. Derecho de autor y derechos conexos. Buenos Aires: UNESCO, 1993 p. 166).

${ }^{8}$ FRAGOSO, João Henrique da Rocha. Direito Autoral: Da Antiguidade à Internet. São Paulo: Quartier Latin, 2009, p. 293.

${ }^{9}$ Conforme ensina Pontes de Miranda, essa "identificação pessoal, essa ligação do agente à obra, essa relação de autoria, é o vínculo psíquico, fático, inabluível, portanto indissolú- 
pressa na Lei 9.610/98, a qual estabelece que o autor tem o direito moral de reivindicar, a qualquer tempo, a autoria da obra, bem como de ter seu nome, pseudônimo ou sinal convencional indicado ou anunciado, como sendo o do autor, na utilização da obra (art. 24, I e II $)^{10}$.

Em complemento, o art. 12 da mesma lei prevê que o autor de obra literária, artística ou científica, para se identificar como tal, poderá "usar de seu nome civil, completo ou abreviado até por suas iniciais, de pseudônimo ou qualquer outro sinal convencional".

Ao lado da Lei 9.610/98, não se pode deixar de mencionar a Convenção de Berna, que em seu art. 6 bis, 1, igualmente reconhece ao autor, independentemente dos direitos patrimoniais, e mesmo depois de sua cessão, o direito de reivindicar a paternidade da obra.

Nessa senda, o caráter amplo e genérico dessas disposições tem levado alguns autores a compreender a existência de distintas e diversas hipóteses no âmbito do direito ao reconhecimento da autoria, o que pode ser verificado não somente no Brasil, mas também nos ensinamentos de doutrinadores estrangeiros.

\section{AS FACETAS DO DIREITO AO RECONHECIMENTO DA AUTORIA}

Em nosso país, o entendimento prevalente encontra no direito ao reconhecimento da autoria a presença de dois aspectos, um positivo e outro negativo. Sob o ponto de vista positivo (art. 24, II da Lei 9.610/98), significa que o autor tem o direito de exigir que a obra seja publicada com a menção da designação por ele determinada, bem como que tal nome não pode ser trocado pelo de outra pessoa, modificado ou excluído ${ }^{11}$. No que toca ao aspecto negativo, em caso de alguém se atribuir falsamente a au-

vel" (PONTES DE MIRANDA, Francisco Cavalcanti. Tratado de direito privado. Campinas: Bookseller, 2000, t. VII, p. 177). De acordo com Adriano de Cupis, a "paternidade intelectual representa um vínculo espiritual indissolúvel entre o autor e a sua obra" (CUPIS, Adriano de. Os direitos da personalidade. Trad. Afonso Celso Furtado Rezende. Campinas: Romana, 2004, p. 336).

${ }^{10}$ Art. 24 da Lei 9.610/98: "São direitos morais do autor: I - o de reivindicar, a qualquer tempo, a autoria da obra; II - o de ter seu nome, pseudônimo ou sinal convencional indicado ou anunciado, como sendo o do autor, na utilização de sua obra;".

${ }^{11}$ VEGA VEGA, José Antonio. Derecho de autor. Madrid: Tecnos, 1990, p. 121. 
toria de uma obra, em detrimento de seu criador, terá este o direito de reagir contra a violação cometida, pugnando pela ligação de seu nome à obra, em conformidade com o art. 24, I da Lei 9.610/98.

No direito alemão, a título de comparação, os ensinamentos sobre a matéria seguem, em linhas gerais, o que foi acima comentado ${ }^{12}$. É garantido ao criador de uma obra o reconhecimento da sua autoria e a liberdade de decidir qual nome utilizará para se identificar. Em caso de violação desse direito, como quando o titular do direito patrimonial altera arbitrariamente o nome do autor, a lei alemã garante ao criador o respeito ao seu direito moral, especialmente contra plagiadores ${ }^{13}$. Assim sendo, o criador, conforme amplamente asseverado pelos estudiosos da Alemanha, pode propor ação em defesa da paternidade de sua obra contra todos aqueles que coloquem sua autoria em discussão ou que a pretendam para $\mathrm{si}^{14}$.

Desse modo, à exceção do controvertido direito de contestar a paternidade (de se opor à falsa atribuição de autoria), que não será objeto deste estudo, as divergências existentes entre os autores se postam mais no campo didático. Portanto, o que interessa para o estudo do plágio e da contrafação é que o autor tem direito de ver sua autoria reconhecida, cabendo a ele determinar como seu nome se apresentará na obra, seja por

\footnotetext{
12 Nesse ponto, para demonstrar a similaridade dos ensinamentos, traduzimos o seguinte trecho da doutrina de Manfred Rehbinder: "O reconhecimento da autoria é protegido através do direito de indicação do nome ( $\$ 13$ da UrhG), completado pela proibição de modificação ( $\$ 38$ UrhG) e pelo dever de informar a fonte ( $\$ 63$ UrhG). Os interesses do autor são protegidos através do direito de indicação do nome sob dois aspectos. Pelo primeiro, pode o autor ser reconhecido a qualquer tempo pelo seu trabalho e se defender contra usurpações, como, por exemplo, quando um terceiro se faz passar injustamente como autor de seu trabalho. Pelo segundo, tem o autor o direito de menção diante daqueles que usam seu trabalho". Transcrevemos o original, que foi traduzido livremente: "Die Anerkennung der Urheberschaft wird geschützt durch das Namensnennungsrecht in $\S 13$ UrhG, ergänzt durch das Änderungsverbot des $\$ 39$ UrhG und die Pflicht zur Quellenangabe gemä $\beta \S 63$ UrhG. Die Urheberinteressen werden durch das Namensnennungsrecht in zweierlei Hinsicht geschützt. Zum einen kann sich der Urheber jederzeit zu seinem Werk bekennen und gegen Übergriffe wehren, z. B. dort, wo Dritte sich zu Unrecht als Autoren seiner Werke augeben. Zum anderen hat der Autor Nennungsrechte gegenüber demjenigen, der sein Werk nutzt" (REHBINDER, Manfred. Urheberrecht. 16. ed. München: C. H. Beck, 2010, p. 161).

13 SCHACK, Haimo. Urheber- und Urhebervertragsrecht. 5. ed. Tübingen: Mohr Siebeck, 2010, p. 186.

${ }^{14}$ KROITZSCH, Hermann. §§ 11-22. In: MÖHRING, Philipp; NICOLINI, Käte (Hrsg.).
} Urheberrechtsgesetz. 2. ed. München: Vahlen, 2000, p. 260. 
meio do nome civil, de pseudônimo ou do anonimato, bem como tem direito à veiculação de pretensões que garantam o respeito ao direito de paternidade.

\section{PLÁGIO}

\subsection{CONSIDERAÇÕES INICIAIS}

O plágio constitui indubitavelmente lesão a direitos da personalidade do autor, estando intimamente ligado ao direito ao reconhecimento da paternidade. Apesar do plágio ser há muito tempo tratado no Brasil, não há em nosso ordenamento jurídico um conceito ou regulamentação da matéria $^{15}$, tratando-se de terminologia e construção adotada pela doutrina e replicada na jurisprudência ${ }^{16}$.

\footnotetext{
15 Conforme anota Chinellato, o único ordenamento jurídico que chegou a conceituar o plágio foi o peruano, o que foi feito no art. 124 da Lei 13.714, de 01.09.1961, que dispunha: "También infringe la ley quien comete el delito de plagio que consiste en difundir como propia, en todo o en parte, una obra ajena, seja textualmente o tratando de dissimular la apropriación mediante ciertas alteraciones". Todavia, tal lei foi revogada pelo Decreto Legislativo 822, de 23.04.1996, que não repetiu a conceituação (CHINELLATO, Silmara Juny de Abreu. Notas sobre plágio e autoplágio. Revista do Instituto dos Advogados de São Paulo, São Paulo, v. 29, p. 305-328, jan./jun. 2012, p. 308).

${ }^{16} \mathrm{O}$ mesmo ocorre, conforme noticia Waiblinger, na Alemanha, onde a lei não conceitua o plágio, existindo menção à expressão apenas na exposição de motivos do $\S 23$ da lei autoral (UrhG). Embora não previsto na lei, o termo é encontrado em decisões judiciais, especialmente de tribunais que julgam matéria administrativa, onde sempre existem processos discutindo a perda de grau acadêmico por plágio. As decisões, entretanto, não chegam a apresentar um conceito razoável e exato do plágio, ficando a tarefa a cargo da doutrina, que, por sua vez, diante da grande quantidade e diversidade de conceitos, acaba utilizando frequentemente um conceito geral para diferentes tipos de ação. Apesar disso, mesmo não sendo possível um conceito único, pois cada autor define o plágio de sua forma, a temática é sempre objeto de estudo nos livros sobre Direito de Autor (WAIBLINGER, Julian. Zum Plagiat in der Wissenschaft. Umfang und Grenzen des urheberrechtlichen Schutzes wissenschaftlicher Schriftwerke. Archiv für Urheber- und Medienrecht, Bern, p. 323-446, 2011/ II, p. 325-328). A ausência de previsão legal também é notada por SCHACK, o qual destaca que o plágio se trata de denominação usual para o furto intelectual (SCHACK, Haimo. Urheber- und Urhebervertragsrecht. 5. ed. Tübingen: Mohr Siebeck, 2010, p. 143).
} 
A Lei 9.610/98 não apresenta nenhuma definição de plágio, conceitua apenas a contrafação, entendida como "a reprodução não autorizada" de uma obra (art. $5^{\circ}$, VII). Todavia, a contrafação não se confunde com o plágio, tema que será analisado neste trabalho para se poder afastar eventuais equívocos que ocorrem no dia a dia. Em todo caso, aqui já se pode fazer uma distinção, pois a contrafação foi conceituada pela Lei 9.610/98, enquanto que o plágio não foi definido pelo legislador.

\section{$3.2 \quad$ ETIMOLOGIA}

Na Antiguidade Clássica, tanto na Grécia como em Roma, era corrente o problema do plágio, mas não havia legislação específica para a proteção do autor.

A palavra que chegou ao português pelo latim (plagium) decorre das previsões da Lex Fabia de Plagiariis, do século segundo antes de Cristo. O plágio do Direito romano, entretanto, não tinha nada a ver com a acepção atual da palavra ${ }^{17}$, pois os romanos, sob o nome de plagium, puniam "a escravização de homem livre, bem como a compra e venda ou assenhoreamento de escravo alheio" ${ }^{18}$.

Todavia, a expressão sofreu desvio histórico, atribuído ao poeta Marco Valério Marcial (42-104 d.C.), que comparou seus epigramas a escravos libertos, os quais estariam nas mãos de um sequestrador de nome Fidentino (plagiarius) ${ }^{19}$.

Marcial escreveu em seus epigramas (Epigrama 30, Livro I): "Segundo consta, Fidentino, tu lês os meus trabalhos ao povo como se fossem teus. Se queres que os digam meus, mandar-te-ei de graça os meus poemas; se quiseres que os digam teus, compra-os, para que deixem de ser meus". E no quinto Epigrama asseverou ainda Marcial: "Quem busca a fama por meio de poesias alheias, que lê como suas, deve comprar não o livro, mas o silêncio do autor" ${ }^{20}$.

${ }^{17}$ CHINELLATO, Silmara Juny de Abreu. Notas sobre plágio e autoplágio. Revista do Instituto dos Advogados de São Paulo, São Paulo, v. 29, p. 305-328, jan./jun. 2012, p. 306.

${ }^{18}$ HUNGRIA, Nélson. Comentários ao Código Penal. 4 ed. Rio de Janeiro: Forense, 1958, v. 6, p. 198.

${ }^{19}$ REHBINDER, Manfred. Urheberrecht. 16. ed. München: C. H. Beck, 2010, p. 07.

${ }^{20}$ ROCHA, Daniel. Direito de autor. São Paulo: Irmãos Vitale, 2001, p. 15. 
De qualquer forma, foi somente no período da Renascença que a palavra plágio veio a ter sua acepção atual, quando os "jurisconsultos Duareno e Tomásio concluíram que o plágio era punido pela Lex Fabia de Plagiariis, entendimento que foi seguido por autores modernos, o qual, no entanto, baseou-se em erro" ${ }^{21}$.

\subsection{O PLÁGIO: CONCEITO EM CONSTRUÇÃO}

O plágio é um instituto jurídico cuja conceituação ainda se encontra em construção, mas, em linhas gerais, fala-se na falsa atribuição da criação de uma obra ou de parte dela, em evidentemente ofensa ao direito de paternidade do autor plagiado ${ }^{22}$. O plagiador tem como objetivo primordial a obtenção de fama e reconhecimento, o que é muitas vezes alcançado com a indevida atribuição de produções alheias, que são afastadas da personalidade de seu verdadeiro criador e lamentavelmente ligadas ao plagiador.

A conduta muitas vezes tem fundamento na falta de condições desse verdadeiro "ladrão intelectual" de criar alguma obra digna de deferência. Não faltam outros, entretanto, que apesar de dotados de inteligência e talento, simplesmente por preguiça ou visando ao reconhecimento ou lucro fácil, "não hesitam recorrer ao mesmo expediente" ${ }^{23}$. Porém, independentemente dos motivos que levam ao cometimento desse ilícito, o fato é que a legislação brasileira, como já foi mencionado, não apresenta um conceito do plágio, o que é digno de aplausos e tem levado a doutrina a se debruçar sobre o tema.

A despeito da sua importância, até o momento a matéria ainda não foi suficientemente desenvolvida. É imprescindível que a doutrina

\footnotetext{
${ }^{21}$ CHINELLATO, Silmara Juny de Abreu. Notas sobre plágio e autoplágio. Revista do Instituto dos Advogados de São Paulo, São Paulo, v. 29, p. 305-328, jan./jun. 2012, p. 306.

22 O plágio é sem dúvida um tema muito polêmico, havendo até mesmo aqueles que são mais tolerantes, especialmente no domínio da literatura. Diante disso, não poderíamos deixar de citar no presente trabalho, para reflexão, as palavras de Giraudoux: "Le plagiat est à l'origine de toutes les littératures, à l'exception de la première, qui d'ailleurs est inconnue" (LUCAS, André; LUCAS, Henri-Jacques. Traité de la propriété littéraire et artistique. 3. ed. Paris: Litec, 2006, p. 242).

${ }^{23}$ CHAVES, Antônio. Plágio. Revista de Informação Legislativa, Brasília, ano 20, n. 77, p. 403-424, jan./mar. 1983, p. 404.
} 
cumpra sua função, precisando a significação do plágio, o que sabidamente não é tarefa fácil, ainda mais se se considerar a existência de inúmeras espécies de obras protegidas pelo Direito de Autor.

Entrementes, não faltam definições para o termo, entendendose, de modo geral, como o fez Otávio Afonso, que plagiador é aquele que apresenta uma imitação ou cópia literal da obra de outrem como sendo de sua autoria ${ }^{24}$.

Nessa mesma linha leciona Antônio Chaves, asseverando que no plágio há a apresentação de "trabalho alheio como próprio, mediante o aproveitamento disfarçado, mascarado, diluído, oblíquo, de frases, ideias, personagens, situações, roteiros e demais elementos das criações alheias" 25 .

Não é diferente a definição de Schack, que vê o plágio como a apropriação, com ou sem alteração, de todo um trabalho protegido pela lei autoral ou de parte dele, com a usurpação de sua autoria ${ }^{26}$.

${ }^{24}$ AFONSO, Otávio. Direito Autoral: conceitos essenciais. Barueri: Manole, 2009, p. 121.

${ }^{25}$ CHAVES, Antônio. Plágio. Revista de Informação Legislativa, Brasília, ano 20, n. 77, p. 403-424, jan./mar. 1983, p. 406.

${ }^{26}$ SCHACK, Haimo. Urheber- und Urhebervertragsrecht. 5. ed. Tübingen: Mohr Siebeck, 2010, p. 143. Transcrevemos o original: "Das Plagiat ist die unveränderte oder veränderte Übernahme eines urheberrechtlich geschützten Werkes oder Werkteiles unter AnmaBung der Urheberschaft".

Um pouco diversa é a definição de Rehbinder, que traduzimos livremente: "Em sentido estritamente jurídico entende-se como plágio somente a apropriação de trabalhos, ou parte de trabalhos, protegidos pelo direito autoral, seja ele não alterado ou com modificação cuja distância do original não alcance a livre utilização, além da omissão da informação de fonte junto à citação permitida. Transcrevemos o original: "Im engeren juristischen Sinne versteht man darunter nur die Übernahme von urheberrechtlich geschützen Werken oder Werkteilen, sei sie unverändert oder in einer Umarbeitung, deren Abstand vom Original nicht die freie Benutzung erreicht, ferner die Unterlassung der Quellenangabe bei an sich erlaubten Zitaten". O professor esclarece ainda que em razão das diferentes compreensões do fenômeno, entendeu melhor o legislador alemão não colocar na lei um conceito de plágio (REHBINDER, Manfred. Urheberrecht. 16. ed. München: C. H. Beck, 2010, p. 156).

Ulmer, por outro lado, apresenta uma definição mais síntetica do plágio, que consistiria simplesmente na "utilização de uma obra protegida ou de parte da mesma com usurpação da autoria". Vejamos o original, que traduzimos livremente: "Plagiat im Rechtssinn ist demnach die Benutzung eines geschützen Werkes oder Von Teilen desselben unter Anmaßung der Urheberschaft" (ULMER, Eugen. Urheber- und Verlagsrecht. 3. ed. Berlin: Springer, 1980, p. 274). 
Carlos Aberto Bittar também examina a matéria, definindo o plágio como a "imitação servil ou fraudulenta de obra alheia, mesmo quando dissimulada por artifício, que, no entanto, não elide o intuito malicioso". Afasta do conceito o aproveitamento remoto ou fluido, isto é, de pequeno vulto ${ }^{27}$.

Digno de nota é igualmente o ponto de vista de Villalba e Lipszyc, que consideram como plágio a apropriação de todos ou de alguns elementos originais da obra de outro autor, apresentando-os como pró$\operatorname{prios}^{28}$.

Por conseguinte, dos conceitos apresentados, vê-se que há no plágio, em linhas gerais, a negação da relação de paternidade existente entre uma determinada obra e seu autor. O plagiador ignora que determinada obra foi criada por outrem, apoderando-se integralmente ou de partes essenciais da obra. Seja como for, em que pese a existência de semelhanças entre as definições apresentadas, é certo que, em uma análise mais acurada, podem-se constatar divergências bastante significativas, o que ficará mais evidente a seguir, com o estudo dos pressupostos do plágio.

\subsection{PRESSUPOSTOS}

No plágio, o que está em jogo é a própria personalidade do autor, que é diretamente atingida pelo plagiador. Ofende-se fundamentalmente o direito de paternidade ao se afastar a obra do seu verdadeiro autor. A conduta também pode lesionar outros direitos dessa mesma natureza (chamados de direitos morais do autor), como é o caso do direito à integridade (art. 24, IV da Lei 9.610/98), quando há alterações na obra, bem como do direito ao inédito (art. 24, III da Lei 9.610/98), se a obra ainda não tinha sido publicada ${ }^{29}$.

\footnotetext{
27 BITTAR, Carlos Alberto. Direito de autor. 4. ed. Rio de Janeiro: Forense Universitária, 2008, p. 48-49.

${ }^{28}$ LIPSZYC, Delia; VILLALBA, Carlos Alberto. Derecho de autor en la Argentina. Buenos Aires: La Ley, 2009, p. 495.

${ }^{29}$ Nessa mesma linha ensinam Carlos Alberto Villalba e Delia Lipszyc: "el plagio importa no solo la reproducción o la comunicación pública total o parcial de una obra ajena sino también una lesión a su integridad y a su paternidad" (LIPSZYC, Delia; VILLAL-
} 
Apesar de colidir diretamente com os direitos da personalidade do autor, o plágio pode ainda prejudicar de forma indireta a utilização econômica da obra, pois é possível a concorrência entre as obras, que poderia muito bem diminuir as vendas da obra plagiada.

Dessa maneira, ao plagiar uma obra, é certo que o autor da conduta ilícita pode se beneficiar de eventuais proveitos econômicos decorrentes da utilização da obra. Entretanto, o pressuposto fundamental do plágio é a obtenção pelo plagiador de vantagens de ordem não patrimonial, tais como a fama, o reconhecimento e o prestígio, agregando valores à sua personalidade, em desrespeito ao direito de paternidade de outrem.

Deve-se ainda acrescentar que para a ocorrência do plágio é necessária a violação dos direitos do autor, o que somente ocorrerá quando estiver diante de uma obra protegida. Pois bem, como nem toda obra do espírito é protegida pelo Direito de Autor, deve-se então compreender que somente poderá haver a prática de plágio quando a obra plagiada for protegida pela lei autoral ${ }^{30}$. Assim sendo, as produções intelectuais mencionadas no rol do art. $8^{\circ}$ da Lei 9.610/98, como não são objeto de proteção como direitos autorais, não podem conduzir à prática de plágio.

Outrossim, mister se faz que haja o aproveitamento das ideias que constituem a essência, o cerne, a espinha dorsal da obra plagiada. A configuração do plágio, dessa forma, somente vai ocorrer com "a absorção do núcleo de representatividade da obra, ou seja, daquilo que a individualiza e corresponde à emanação do intelecto do autor" ${ }^{31}$.

Nunca é demais lembrar, entrentanto, que as ideias fazem parte do acervo cultural da humanidade, não pertencem com exclusividade a nenhuma pessoa, não havendo que se falar no seu monopólio ( $\operatorname{art.} 8^{\circ}$, I da Lei 9.610/98). Por isso, para se poder admitir a ocorrência de plágio, é igualmente indispensável que as ideias atribuídas indevidamente ao plagiador façam parte de obra alheia, tenham sido expressas em trabalho de

BA, Carlos Alberto. Derecho de autor en la Argentina. Buenos Aires: La Ley, 2009, p. 495).

${ }^{30}$ CHINELLATO, Silmara Juny de Abreu. Notas sobre plágio e autoplágio. Revista do Instituto dos Advogados de São Paulo, São Paulo, v. 29, p. 305-328, jan./jun. 2012, p. 310.

${ }^{31}$ CHINELLATO, Silmara Juny de Abreu. Notas sobre plágio e autoplágio. Revista do Instituto dos Advogados de São Paulo, São Paulo, v. 29, p. 305-328, jan./jun. 2012, p. 317. 
outrem $^{32}$. Nesse sentido, conforme esclarece Fragoso, “o plagiário usurpa a criação alheia, não a ideia, não o tema, mas o modo como foram estes tratados, ou seja, usurpa o modo de expressão de tal ideia, de tal ou qual tema" 33 .

Vale ainda destacar que não configura o ilícito o mero aproveitamento de fontes comuns, de modo que não se pode, sem uma análise mais aprofundada do caso concreto, dizer que houve plágio pelo simples fato das fontes bibliográficas utilizadas nas obras serem as mesmas. Igualmente, não conduzem ao plágio a simples ocorrência de identidade temática e a similitude ou equivalência de ideias e pensamentos ${ }^{34}$. Para a configuração do plágio é necessário mais do que referidas coincidências.

Ademais, não se pode esquecer que a proteção concedida ao autor, inclusive contra casos de plágio, independe da existência de um registro da obra e de sua autoria. Tal registro é meramente facultativo em nosso ordenamento jurídico (art. 18 da Lei 9.610/98) ${ }^{35}$, podendo ser afastado por prova em contrário, o que lhe dá a natureza de uma presunção meramente relativa de autoria (iuris tantum). Apesar disso, o registro anterior da obra pelo verdadeiro autor constitui uma prova bastante significativa, que não pode ser desprezada ${ }^{36}$.

32 VILlalBA DÍAZ, Federico Andrés. Cuándo el plagio es delito? Dissertação de mestrado. Palermo: Universidade de Palermo, 2013, p. 64-65.

${ }^{33}$ FRAGOSO, João Henrique da Rocha. Direito Autoral: Da Antiguidade à Internet. São Paulo: Quartier Latin, 2009, p. 296.

${ }^{34} \mathrm{E}$ aqui vale citar a obra prima de literatura alemã, Fausto, de Goethe, que é baseada em lendas e em obras anteriores (FRAGOSO, João Henrique da Rocha. Direito Autoral: Da Antiguidade à Internet. São Paulo: Quartier Latin, 2009, p. 263).

35 Art. 18 da Lei 9.610/98: "A proteção aos direitos de que trata esta Lei independe de registro".

${ }^{36}$ Ainda no que toca à questão da autoria e do registro da obra, vale lembrar que o art. 18 da Lei 5.988/73 previa que as dúvidas levantadas quando da realização do registro poderiam ser submetidas a decisão do Conselho Nacional de Direito Autoral. A Lei 9.610/98, contudo, não repetiu a referida disposição, abolindo o procedimento de suscitação de dúvida. Não obstante a inexistência do procedimento, a temática chegou a ser analisado pelo Tribunal Regional Federal da $2^{\mathrm{a}}$ Região em um caso em que a Fundação Biblioteca Nacional se deparou com o registro de uma obra literária que teve sua autoria questionada por terceiro. A despeito do problema atinente à autoria da obra, em face da ausência de previsão legal, o processo foi extinto sem julgamento de mérito, ao argumento de que o Judiciário não é órgão de consulta. A decisão de primeiro grau foi majoritariamente referendada em segunda instância (BRASIL. Tribunal Regional Federal da $2^{a}$ Região. Apelação Cível 200151010198066/RJ. Relatora: Desembargadora Federal Liliane Roriz. Rio de Janeiro, DJ de 06/05/2009, p. 159). 
Por derradeiro, a dissimulação não é elemento essencial para a configuração do plágio, pois se assim não fosse, o plágio grosseiro, a cópia literal, não constituiria o ilícito, haja vista a ausência do "mascaramento". Assim sendo, apesar do plagiador normalmente procurar camuflar, dissimular, mascarar ou disfarçar sua conduta ilícita, entende-se que tal conduta não constitui pressuposto para a caracterização do plágio.

\subsection{PLÁGIO: EXTENSÃO E DISSIMULAÇÃO}

No que diz respeito à extensão, a obra alheia pode ser plagiada total ou parcialmente. O plágio parcial é o mais comum, visto que a prova em juízo de plágio integral é muito mais fácil do que aquela do plágio parcial. De fato, como não há critérios objetivos que possam ser aplicados para a caracterização do plágio, é sempre necessária a avaliação pelo magistrado de cada caso concreto, o que é muito mais simples quando uma obra foi integralmente plagiada.

Ao lado da extensão do plágio, ou seja, parcial ou total, também se pode apontar a existência do plágio sutil e do plágio grosseiro. No plágio sutil, o trabalho de análise do magistrado é bem mais difícil, podendo-se valer até mesmo do auxílio de peritos, uma vez que o plagiador modifica habilmente a obra nova, alterando sua composição e expressão, atingindo amplo sucesso na dissimulação de sua conduta. Nessa situação, o plagiador pode até mesmo restar sem reprovação jurídica, já que o julgamento dependerá bastante dos conhecimentos e das habilidades do perito em seu ramo de atividade. Contudo, mesmo que não haja sanção jurídica, a conduta não deixa de ser moralmente reprovável ${ }^{37}$.

O plágio grosseiro, por seu turno, normalmente consiste na cópia ipsis litteris de um trabalho alheio, com a substituição do nome do seu verdadeiro autor, mas também admite a tentativa de dissimulação. A dissimulação no plágio grosseiro é conduta usual, pois o plagiador, como já foi destacado, tenta se passar por autor do trabalho, procurando enganar tanto seu verdadeiro autor como toda a sociedade ${ }^{38}{ }^{39}$. Todavia, a tentati-

\footnotetext{
${ }^{37}$ FRAGOSO, João Henrique da Rocha. Direito Autoral: Da Antiguidade à Internet. São Paulo: Quartier Latin, 2009, p. 300.

38 MORAES, Rodrigo. Os Direitos Morais do Autor: Repersonalizando o Direito Autoral. Rio de Janeiro: Lumen Juris, 2008, p. 86.
} 
va de dissimulação não é exitosa, visto que a falta de talento do plagiador permite facilmente a constatação da prática do ilícito. O plágio grosseiro é então identificado pela simples e superficial comparação entre as obras.

Aliás, na tentativa de dissimular sua conduta, muitas vezes o plagiador invoca o nome do plagiado no trabalho, fazendo agradecimentos ou prestando homenagens ${ }^{40}$. Também é bastante comum a citação da obra plagiada na bibliografia, o que certamente não afasta o ato ilícito, pois o que interessa para a sua configuração é o conteúdo, a natureza do trecho plagiado e não a quantidade de empréstimos tomados ou o que foi pesquisado $^{41}$. E quanto ao tema, Antônio Chaves é extremamente esclarecedor:

Pode ocorrer, com efeito, que o plágio não tenha tomado senão um pequeno número de passagens, mas que estas, principalmente em se tratando de uma obra filosófica ou científica, sejam exatamente as que dão à obra seu caráter de originalidade própria, que são como a medula. Ora, neste caso, pouco

39 Villalba Dias, em função da tentativa ou não de se acobertar o plágio, classifica-o em duas modalidades: plágio servil e plágio inteligente. A cópia literal ou quase literal do trabalho é chamada de plágio servil, enquanto que a cópia dissimulada, mas que mantém a essência da obra original, é nominada plágio inteligente (VILLALBA DÍAZ, Federico Andrés. Cuándo el plagio es delito? Dissertação de mestrado. Palermo: Universidade de Palermo, 2013, p. 23-24).

40 VILlalBA DÍAZ, Federico Andrés. Cuándo el plagio es delito? Dissertação de mestrado. Palermo: Universidade de Palermo, 2013, p. 49.

41 Acerca da obra musical, seguindo a linha da ausência de um critério objetivo para a definição do plágio, não há que se falar em um mínimo de notas ou compassos necessários para a caracterização do plágio. É totalmente equivocado e sem amparo legal o "mito dos oito compassos". Por conseguinte, para que não haja injustiças, somente é possível a verificação da ocorrência desta conduta ilícita em cada caso concreto, uma vez que "não existe qualquer regra aritimética para detectar o plágio musical" (MORAES, Rodrigo. Os Direitos Morais do Autor: Repersonalizando o Direito Autoral. Rio de Janeiro: Lumen Juris, 2008, p. 90). E não é outro o entendimento de Villalba Dias, o qual deixa claro que a configuração do ilícito não depende da quantidade do material utilizado, mas sim se foi utilizada a essência da obra alheia. $\mathrm{O}$ autor argentino ainda cita um trecho de uma decisão proferida em 1976 pela Suprema Corte da Província de Buenos Aires, que transcrevemos: "la mayor o menor proporción de la utilización del material ajeno en la obra propria no es una cuestión substancial; lo que importa es si de la comparación puede establecerse la similitud y por lo tanto, el origen de lo supuestamente plagiado" (VILLALBA DÍAZ, Federico Andrés. Cuándo el plagio es delito? Dissertação de mestrado. Palermo: Universidade de Palermo, 2013, p. 24). 
importaria a quantidade dos empréstimos; é a sua qualidade, a sua natureza, que é preciso levar em conta $^{42}$.

Daí pode ser extraído que a apropriação deve dizer respeito à essência ou substância da obra plagiada. Não basta, desse modo, a reprodução de trechos ou de fragmentos nos quais não se possa reconhecer a substância, as partes orgânicas da obra plagiada, pois tal conduta não será suficiente para a configuração do plágio ${ }^{43}$. Por outro lado, partindo da necessidade de reprodução da essência de outra obra, é certo que o plágio não demanda a identidade das formas de expressão, admitindo-se sua ocorrência mesma na adaptação de uma obra de um gênero para outro, como é o caso da obra literária que é transformada em obra audiovisual ${ }^{44}$.

Outrossim, é interessante notar que existem muitos casos de plágio em que não há grande preocupação com a dissimulação da conduta. Infelizmente isso tem ocorrido com frequência nas universidades brasileiras (muito comum em trabalhos de conclusão de curso de gradução), em que muitos estudantes simplesmente copiam da internet trabalhos alheios, apenas substituindo o nome do autor. São casos de plágio total e grosseiro, que muitas vezes passam despercebidos, mas não podem ser desprezados, uma vez que graus acadêmicos são concedidos àqueles que agiram com total desonestidade intelectual ${ }^{45}$. Nessas situações, é cabível não somente a perda da titulação pretendida, mas também o acionamento do responsável nas esferas cível e criminal.

Aliás, diante do problema supra, vale abrir um pequeno parêntese a seguir para tecer alguns comentários sobre outro tema muito discutido no ambiente acadêmico, o chamado autoplágio.

${ }^{42}$ CHAVES, Antônio. Plágio. Revista de Informação Legislativa, Brasília, ano 20, n. 77, p. 403-424, jan./mar. 1983, p. 407.

${ }^{43}$ CHINELLATO, Silmara Juny de Abreu. Notas sobre plágio e autoplágio. Revista do Instituto dos Advogados de São Paulo, São Paulo, v. 29, p. 305-328, jan./jun. 2012, p. 314.

${ }^{44}$ FRAGOSO, João Henrique da Rocha. Direito Autoral: Da Antiguidade à Internet. São Paulo: Quartier Latin, 2009, p. 299.

${ }^{45}$ Acerca do plágio em ambiente acadêmico é ainda interessante notar que as instituições de ensino normalmente proíbem tal conduta em códigos de ética ou de boas práticas. Esse é o caso, por exemplo, do art. 83 das Normas Acadêmicas da Universidade de Palermo, que sanciona com expulsão o aluno que tenha incorrido em fraude, desonestidade acadêmica, plágio ou cópia (VILLALBA DÍAZ, Federico Andrés. Cuándo el plagio es delito? Dissertação de mestrado. Palermo: Universidade de Palermo, 2013, p. 67). 


\subsection{AUTOPLÁGIO}

Ainda dentro da temática do plágio, não se poderia deixar de apresentar esta breve nota acerca do chamado autoplágio, que não encontra previsão ou conceituação em nosso Direito positivo. Fala-se muito na vedação do autoplágio, especialmente em ambiente acadêmico, mencionando-se usualmente que um autor não pode utilizar trechos de textos que escreveu em obra posterior.

Nas palavras de Rehbinder, o autoplágio ocorre quando um autor utiliza em uma criação posterior, um trabalho, ou parte dele, já apresentado anteriormente. Contudo, tal prática somente pode representar lesão a direitos autorais quando há obrigação contratual que vede tal conduta $^{46}$, o que pode ocorrer na assinatura de um contrato de edição. Assim sendo, se um autor não se obrigou contratualmente, não há que se falar em autoplágio, ficando livre para reproduzir posteriormente sua obra, em parte ou na totalidade, quantas vezes quiser.

De qualquer maneira, não parece adequada a terminologia utilizada, pois o autoplágio não pode sequer ser considerado como uma espécie de plágio, haja vista que, como foi visto, o plágio pressupõe violação do direito de paternidade do autor, não sendo concebível que um criador viole seu próprio direito.

Por outro lado, apesar de não se tratar de modalidade de plágio, é importante lembrar que usualmente, para a concessão de titulação acadêmica, exige-se a apresentação de um trabalho inédito. Nesses casos, até mesmo em função da vinculação às normas da instituição de ensino, a apresentação de obra já levada ao público anteriormente não vai ocasionar lesão à legislação autoral, mas não permitirá a concessão da titulação pretendida, tendo em vista o exigido pela instituição de ensino.

Pois bem, traçadas as linhas gerais do que se compreende por plágio, figura que é considerada por muitos autores como a mais grave lesão aos direitos do autor ${ }^{47}$, passa-se agora à contrafação, que por se tratar de figura correlata, não poderia deixar de ser tratada nesse trabalho.

\footnotetext{
${ }^{46}$ REHBINDER, Manfred. Urheberrecht. 16. ed. München: C. H. Beck, 2010, p. 156.

${ }^{47}$ VILLALBA DÍAZ, Federico Andrés. Cuándo el plagio es delito? Dissertação de mestrado. Palermo: Universidade de Palermo, 2013, p. 32.
} 


\section{CONTRAFAÇÃO}

\subsection{CONCEITUAÇÃO}

A contrafação é a reprodução não autorizada de uma obra, entendendo-se por reprodução "a cópia de um ou vários exemplares de uma obra literária, artística ou científica ou de um fonograma, de qualquer forma tangível, incluindo qualquer armazenamento permanente ou temporário por meios eletrônicos ou qualquer outro meio de fixação que venha a ser desenvolvido" (art. $5^{\circ}$, VI e VII da Lei 9.610/98).

Como se pode notar da definição legal, a conduta do contrafator, ao reproduzir sem autorização uma obra, não tem como objetivo a lesão a direitos da personalidade do autor, como é o caso do direito de paternidade. Não há preocupação do contrafator em esconder a paternidade de uma obra para poder atribuí-la a si mesmo, pois o que usualmente ocorre é que o contrafator indica corretamente a autoria da obra, mas prejudica o autor no que diz respeito ao aproveitamento econômico. Assim, a contrafação está ligada essencialmente aos aspectos patrimoniais, pois retira indevidamente da obra "os proventos econômicos que de direito caberiam ao autor" ${ }^{48}-49$.

Realmente, na contrafação existe a publicação ou a reprodução, de forma abusiva, de trabalho alheio. Não há que se falar no consentimento do autor para a realização do ato do contrafator e, por isso, não tem nenhuma relevância a forma extrínseca, o destino, ou a finalidade da conduta violadora ${ }^{50}$.

${ }^{48}$ CHAVES, Antônio. Plágio. Revista de Informação Legislativa, Brasília, ano 20, n. 77, p. 403-424, jan./mar. 1983, p. 406.

${ }^{49}$ Sobre o tema, bastante clara é a lição de Otávio Afonso: "O plágio consiste em apresentar como própria a obra intelectual produzida por outra pessoa", enquanto que a "contrafação equivale a reproduzir uma obra, sem autorização, independente do meio utilizado. Neste caso, ela atenta contra a individualidade da obra alheia, visando obter ilicitamente vantagem econômica. O contrafator não pretende ser reconhecido como autor da obra contrafeita" (AFONSO, Otávio. Direito Autoral: conceitos essenciais. Barueri: Manole, 2009, p. 121).

${ }^{50}$ CHINELLATO, Silmara Juny de Abreu. Notas sobre plágio e autoplágio. Revista do Instituto dos Advogados de São Paulo, São Paulo, v. 29, p. 305-328, jan./jun. 2012, p. 314. 
Referido ato ilícito configura, é bom notar, violação não somente ao direito de autor, mas também aos direitos que lhe são conexos (ou vizinhos), encontrando sancionamento tanto pela legislação civil como criminal (art. 184 do Código Penal) ${ }^{51}$.

Desta forma, em linhas gerais, entende-se que quando uma pessoa desfruta ilicitamente de uma obra alheia, normalmente sem afastar o direito de paternidade de seu autor, estamos diante de contrafação ${ }^{52}$. Por conseguinte, a contrafação consiste na reprodução ilícita da obra, integral ou parcial, através de qualquer meio tangível, visando à violação dos direitos econômicos decorrentes da obra.

\subsection{ETIMOLOGIA}

A palavra contrafação decorre do aportuguesamento da palavra francesa "contrefaçon", que em seu sentido original significa apenas falsificação. Como nem toda violação a direito autoral constitui uma falsificação, sua utilização pela lei autoral se distanciou do seu sentido original no idioma francês, já que nosso Direito considera a contrafação simplesmente como a reprodução não autorizada ${ }^{53}$.

De qualquer forma, apesar das críticas da doutrina e do desuso da expressão em legislações estrangeiras, trata-se da terminologia adotada pela Lei 9.610/98.

\subsection{A DISTINÇÃO ENTRE O PLÁGIO E A CONTRAFAÇÃO}

A distinção entre o plágio e a contrafação se torna bastante complicada na medida em que nem sempre há na contrafação a menção ao nome, pseudônimo ou sinal convencional adotado pelo autor, o que configura, além da violação a direitos patrimoniais, também a ofensa ao direito de paternidade.

\footnotetext{
${ }^{51}$ FRAGOSO, João Henrique da Rocha. Direito Autoral: Da Antiguidade à Internet. São Paulo: Quartier Latin, 2009, p. 294.

${ }^{52}$ GUTIERREZ, Bianca Manuela. La tutela del diritto di autore. 2. ed. Milano: Giuffrè, 2008, p. 87-88.

${ }^{53}$ FRAGOSO, João Henrique da Rocha. Direito Autoral: Da Antiguidade à Internet. São Paulo: Quartier Latin, 2009, p. 294.
} 
Igualmente, existe contrafação e desrespeito ao direito ao inédito (art. 24, III da Lei 9.610/98) nos casos em que uma obra ainda não publicada é levada ao público, sem o consentimento do seu autor, por um contrafator. Isso é muito comum em lançamentos de obras cinematográficas, quando, mesmo antes do lançamento do filme nos cinemas, já é possível a compra de uma cópia "pirata".

Os problemas para a identificação das duas formas de violação dos direitos de autor são, então, evidentes, pois é certo que a contrafação pode atingir, ao mesmo tempo, direitos da personalidade do autor e a utilização econômica da obra. $\mathrm{O}$ mesmo também pode ocorrer com o plágio, que pode lesionar simultaneamente o aproveitamento econômico da obra e os direitos da personalidade de seu verdadeiro autor. Ademais, a ofensa a outros direitos da personalidade do autor, da mesma forma, não ajuda na distinção, pois tanto no plágio como na contrafação é cabível, por exemplo, o desrespeito ao direito ao inédito e à integridade.

No que toca à extensão, a contrafação pode decorrer de reprodução total ou parcial da obra, acontecendo o mesmo no plágio, uma vez que o plagiador pode ter se utilizado total ou parcialmente da obra alheia.

O terreno é, sem nenhuma dúvida, bastante movediço, porém, deve-se notar que no plágio sempre haverá a lesão a direitos da personalidade do autor, especificamente o direito à paternidade, bem como haverá a apresentação de conteúdo de obra alheia como se fosse própria. Assim, pode-se dizer que o plágio não ocorre apenas em virtude da reprodução de uma obra, "mas porque os créditos não foram atribuídos ao responsável original" 54 e ainda são conferidos ao plagiador.

Na contrafação, por seu turno, é necessária a ocorrência de violação ao monopólio de aproveitamento econômico da obra, sendo apenas eventual o desrespeito aos direitos morais do autor. Na contrafação não é imprescindível a atribuição de obra alheia ao contrafator, pois esse elemento é essencial somente no plágio.

Com isso, para que ocorra o plágio, é fundamental que exista a atribuição de uma obra alheia como própria, não sendo suficiente apenas a lesão ao direito de paternidade do autor, uma vez que isso pode suceder também em casos de contrafação. E a mesma distinção é feita por Chinellato, valendo aqui a transcrição dos seus ensinamentos:

${ }^{54}$ KROKOSCZ, Marcelo. Autoria e plágio. São Paulo: Atlas, 2012, p. 11. 
Separando-se as figuras em causa, observa-se que no plágio a obra alheia é simplesmente apresentada pelo imitador como própria ou sob graus diferentes de dissimulação. Há absorção de elementos fundamentais da estrutura da obra, atentando-se, pois, contra a personalidade do autor (frustração da paternidade). Na contrafação, há representação ou reprodução da obra alheia sem autorização autoral, podendo ser total ou parcial. Incluindo-se, em seu âmbito, a derivação sem consentimento (a adaptação, ou a tradução, ou a variação do tema), eis que sempre se visa a aproveitamento econômico indevido da obra (atentando contra o aspecto patrimonial, ou contra a obra em si) ${ }^{55}$.

Dessa maneira, se a reprodução parcial ou total de obra de outrem não vier acompanhada da imprescindível atribuição ilegítima de autoria, mas tão somente da ausência do reconhecimento da autoria pela não indicação do nome, pseudônimo ou sinal indicativo, então se estará diante de caso de contrafação e não de plágio. Em todo caso, no plágio sempre haverá violação a direitos da personalidade do autor e a apresentação de trabalho alheio como se fosse próprio. Na contrafação, por outro lado, necessariamente haverá violação a direitos patrimoniais do autor, mas nem sempre haverá lesão a direitos da personalidade do autor.

\section{CONSIDERAÇÕES FINAIS}

No presente artigo, ficou evidente a distinção entre o plágio e a contrafação, institutos que são muitas vezes confundidos pela doutrina e pelos tribunais. Nessa senda, observa-se, em um primeiro momento, que a contrafação foi conceituada pela Lei 9.610/98, enquanto que o plágio não foi definido pelo legislador, dependendo dos trabalhos doutrinários para que se chegue a sua conceituação.

Foi demonstrado que no plágio sempre haverá a lesão ao direito à paternidade, sendo apenas acessório o evental prejuízo aos aspectos

${ }^{55}$ CHINELLATO, Silmara Juny de Abreu. Notas sobre plágio e autoplágio. Revista do Instituto dos Advogados de São Paulo, São Paulo, v. 29, p. 305-328, jan./jun. 2012, p. 314. 
patrimoniais do autor. No plágio, há então a negação da relação de paternidade existente entre uma determinada obra e seu autor. Na contrafação, por seu turno, a reprodução de uma obra vai necessariamente levar à violação do monopólio de aproveitamento econômico, sendo apenas eventual o desrespeito aos direitos morais do autor.

Para a configuração do plágio é necessário que o trecho apropriado constitua a essência, o cerne, a espinha dorsal da obra plagiada. Assim, não basta a reprodução de trechos ou de fragmentos nos quais não se possa reconhecer a substância da obra plagiada. Além disso, não há que se falar em plágio nas hipóteses de mero aproveitamento de fontes comuns, de simples ocorrência de identidade temática e de similitude ou equivalência de ideias e pensamentos.

Por fim, destaca-se que a dissimulação não é elemento essencial para a configuração do plágio. De fato, mesmo a cópia literal, sem "mascaramento", na qual há apenas a substituição do nome do autor pelo nome de um terceiro, conforme o caso concreto, vai configurar plágio e não contrafação.

\section{REFERÊNCIAS BIBLIOGRÁFICAS}

AFONSO, Otávio. Direito Autoral: conceitos essenciais. Barueri: Manole, 2009.

ARAUJO, Luiz Alberto David. O conteúdo do direito à própria imagem: um exercício de aplicação de critérios de efetivação constitucional. Revista do Advogado, São Paulo, v. 23, n. 73, p. 119-126, nov. 2003.

ASCENSÃO, José de Oliveira. O futuro do "direito moral". Revista de Direito Renovar, Rio de Janeiro, vol. 25, p. 107-126, jan./abr. 2003, p. 116.

AZEVEDO, Álvaro Villaça; NICOLAU, Gustavo Rene. Das pessoas e dos bens: artigos $1^{\circ}$ a 103. In: AZEVEDO, Álvaro Villaça (coord.). Código civil comentado. São Paulo: Atlas, 2007, v. I.

BECKER, Bernhard von. § $16 \mathrm{C}$ e D. In: LOEWENHEIM, Ulrich (Hrsg.). Handbuch des Urheberrechts. 2. ed. München: C. H. Beck, 2010, p. 226-236.

BITTAR, Carlos Alberto. Direito de autor. 4. ed. Rio de Janeiro: Forense Universitária, 2008. 
BULLINGER, Winfried. $\S ~ 11-14,23-26$. In: WANDTKE, Artur-Axel; BULLINGER, Winfried (Hrsg.). Praxiskommentar zum Urheberrecht. 3. ed. München: C. H. Beck, 2009, p. 219-265, 365-396.

CHAVES, Antônio. Plágio. Revista de Informação Legislativa, Brasília, ano 20, n. 77, p. 403-424, jan./mar. 1983.

CHINELLATO, Silmara Juny de Abreu. Notas sobre plágio e autoplágio.

Revista do Instituto dos Advogados de São Paulo, São Paulo, v. 29, p. 305-328, jan./jun. 2012.

Direito de autor e direitos da personalidade: reflexões à luz do Código Civil. Tese para Concurso de Professor Titular de Direito Civil da Faculdade de Direito da Universidade de São Paulo. São Paulo: Universidade de São Paulo, 2008.

CUPIS, Adriano de. Os direitos da personalidade. Trad. Afonso Celso Furtado Rezende. Campinas: Romana, 2004.

DIETZ, Adolf; PEUKERT, Alexander. Vor $\S \S 12$ ff., §§ 12-14, 42. In: SCHRICKER, Gerhard; LOEWENHEIM, Ulrich (Hrsg.). Urheberrecht: Kommentar. 4. ed. München: C. H. Beck, 2010.

FRAGOSO, João Henrique da Rocha. Direito Autoral: da antiguidade à internet. São Paulo: Quartier Latin, 2009.

GUTIERREZ, Bianca Manuela. La tutela del diritto di autore. 2. ed. Milano: Giuffrè, 2008.

HUNGRIA, Nélson. Comentários ao Código Penal. 4 ed. Rio de Janeiro: Forense, 1958, v. 6.

KROITZSCH, Hermann. $\S \S 11-22$. In: MÖHRING, Philipp; NICOLINI, Käte (Hrsg.). Urheberrechtsgesetz. 2. ed. München: Vahlen, 2000.

LIPSZYC, Delia; VILLALBA, Carlos Alberto. Derecho de autor en la Argentina. Buenos Aires: La Ley, 2009.

LIPSZYC, Delia. Derecho de autor y derechos conexos. Buenos Aires: UNESCO, 1993.

LUCAS, André; LUCAS, Henri-Jacques. Traité de la propriété littéraire et artistique. 3. ed. Paris: Litec, 2006.

MORAES, Rodrigo. Os Direitos Morais do Autor: Repersonalizando o Direito Autoral. Rio de Janeiro: Lumen Juris, 2008.

PONTES DE MIRANDA, Francisco Cavalcanti. Tratado de direito privado. Campinas: Bookseller, 2000, t. VII.

REHBINDER, Manfred. Urheberrecht. 16. ed. München: C. H. Beck, 2010. 
SCHACK, Haimo. Urheber- und Urhebervertragsrecht. 5. ed. Tübingen: Mohr Siebeck, 2010.

STROWEL, Alain. Droit d'auteur et copyright: divergences et convergences. Paris: LGDJ, 1993.

ULMER, Eugen. Urheber- und Verlagsrecht. 3. ed. Berlin: Springer, 1980.

VEGA VEGA, José Antonio. Derecho de autor. Madrid: Tecnos, 1990.

VILlALBA DÍAZ, Federico Andrés. Cuándo el plagio es delito? Dissertação de mestrado. Palermo: Universidade de Palermo.

WAIBLINGER, Julian. Zum Plagiat in der Wissenschaft. Umfang und Grenzen des urheberrechtlichen Schutzes wissenschaftlicher Schriftwerke. Archiv für Urheber- und Medienrecht, Bern, p. 323-446, 2011/ II. 
